\title{
Review Article \\ Two-Stage Tissue-Expander Breast Reconstruction: A Focus on the Surgical Technique
}

\author{
Elisa Bellini, ${ }^{1,2}$ Marianna Pesce, ${ }^{3}$ PierLuigi Santi, ${ }^{3}$ and Edoardo Raposio ${ }^{1,2}$ \\ ${ }^{1}$ Department of Medicine and Surgery, Plastic Surgery Section, University of Parma, Parma, Italy \\ ${ }^{2}$ Cutaneous, Mini-Invasive, Regenerative and Plastic Surgery Unit, Parma University Hospital, Parma, Italy \\ ${ }^{3}$ Plastic Surgery Chair, Department of Surgical Sciences and Related Methodologies (DICMI), University of Genova, Genova, Italy
}

Correspondence should be addressed to Elisa Bellini; elisa.bellini@outlook.it

Received 19 July 2017; Revised 20 October 2017; Accepted 19 November 2017; Published 10 December 2017

Academic Editor: Adewale Adeyinka

Copyright (C) 2017 Elisa Bellini et al. This is an open access article distributed under the Creative Commons Attribution License, which permits unrestricted use, distribution, and reproduction in any medium, provided the original work is properly cited.

\begin{abstract}
Objective. Breast cancer, the most common malignancy in women, comprises $18 \%$ of all female cancers. Mastectomy is an essential intervention to save lives, but it can destroy one's body image, causing both physical and psychological trauma. Reconstruction is an important step in restoring patient quality of life after the mutilating treatment. Material and Methods. Tissue expanders and implants are now commonly used in breast reconstruction. Autologous reconstruction allows a better aesthetic result; however, many patients prefer implant reconstruction due to the shorter operation time and lack of donor site morbidity. Moreover, this reconstruction strategy is safe and can be performed in patients with multiple health problems. Tissue-expander reconstruction is conventionally performed as a two-stage procedure starting immediately after mammary gland removal. Results. Mastectomy is a destructive but essential intervention for women with breast cancer. Tissue expansion breast reconstruction is a safe, reliable, and efficacious procedure with considerable psychological benefits since it provides a healthy body image. Conclusion. This article focuses on this surgical technique and how to achieve the best reconstruction possible.
\end{abstract}

\section{Objective}

With 1 million new cases in the world each year, breast cancer is the most common malignancy in women and comprises $18 \%$ of all female cancers. Breast cancer is responsible for $20 \%$ of the deaths in the female population and is the main cause of cancer in women between the ages of 40 and 55 . The main epidemiological risk factors include age, age at menarche and menopause (early menarche and late menopause increase risk), age at first pregnancy (women who have their first child after age of 30 have approximately twice the risk of women who have their first child before age of 20), positive family anamnesis, previous benign breast disease, history of radiation, lifestyle factors (diet, weight, alcohol intake, and smoking), and endogenous factors (estrogen levels, genetic predisposition) [1].

In our society, breasts are integral parts of female beauty and sexuality. A woman's body image and self-esteem can be negatively affected by any alteration in her natural form. Surgery may be necessary to save a woman's life, but for many women these events can be traumatic, both physically and psychologically [2].

Unfortunately, mastectomy is a mutilating operation that, without reconstruction, causes deformity in women [3]. The general goals of breast reconstruction are to restore the missing form of the female breast as well as the location and size of the breast, so that women no longer need to wear an external prosthesis [4]. When they look in the mirror, they feel feminine and attractive and usually no longer need to go to a support group for reassurance. The ultimate goal of breast reconstruction is for a woman to return to her normal life, including both family activities and work [5].

The quality of breast reconstruction will depend not only on the surgeon's skills but also on the amount of missing tissue, patient health conditions, size of the opposite breast, and breast reconstruction technique. Obesity will make reconstruction difficult and is an independent risk factor for perioperative complications, as is smoking, hypertension, chemotherapy, radiotherapy, and age over 65 years $[6,7]$. 
In patients with multiple health problems, reconstruction using implants may be preferred due to shorter operation duration. However, the fact that it may be a multistage operation with required revisions resulting in the patient receiving anesthesia multiple times should not be ignored [8].

Prosthetic implants began to be used for breast reconstruction in the 1960s. The first silicone prosthesis was developed in 1961 and was used in augmentation mammoplasty in 1962 [9]. Since that time, the prosthesis began to be used for reconstructions in mastectomized women [10]. Breast reconstructions using prosthetic implants were applied in a single stage at first. The development of tissue expanders by Radovan created new possibilities in immediate and delayed reconstructions, however, and the popularity of single-stage reconstruction with implants was overridden by two-stage reconstructions in the 1980s [11, 12].

Initially, the silicone implant was incorporated into breast reconstruction only to reestablish the conic shape when radical mastectomy and modified radical mastectomy were routinely performed. In these cases, the implant was always used in conjunction with flap coverage [13]. The evolution toward less destructive mastectomies in oncologic treatment allowed preservation of enough soft tissue for implant-based breast reconstruction. Changes in oncologic practice, such as an increased number of bilateral mastectomies, have contributed to the expansion of implant use [14].

With the development of the concept of tissue expansion, a deflated implant can be inserted into the new pocket created after mastectomy. The expander can subsequently undergo inflation both to stretch the dimensions of the retained skin envelope and to avoid wound contraction during the process of wound maturation after the mastectomy [15]. With improvement in the design of tissue expanders, the port is incorporated into the surface of the implant, eliminating dissection distant to the mastectomy site for valve placement and reducing remote port complications [16, 17]. Textured expanders replaced smooth-surfaced expanders to minimize capsular contracture and migration. With the use of a textured expander, the expander will not migrate away from the area of greatest skin tightness (usually the inferior half of the preserved breast skin envelope) and will maintain a well-defined inframammary line, despite mastectomy [18]. These innovations have made the expander implant for breast reconstruction a reliable technique to restore form at the mastectomy site [19].

In single-stage reconstruction with a permanent implant, the resected breast tissue is replaced with an implant of appropriate volume. However, it is difficult to obtain symmetry in single-stage reconstructions, and the rate of complications (such as infection, skin necrosis, and implant exposure) is higher than with two-stage methods [15].

The most commonly practiced form of implant breast reconstruction today is two-stage reconstruction [20]. Breast reconstruction can be performed immediately after mastectomy or be delayed for months or years, but immediate operation offers many advantages over delayed operation. First, there is an important psychological benefit for the patient: they can leave the hospital with less physical evidence of the cancer pathology, which helps them maintain their bodily integrity [21]. Furthermore, the aesthetic result tends to be better due to the cooperation of the surgeon who performs the mastectomy. Preoperative surgical incision planning with preservation of the maximum possible amount of healthy skin tissue and muscle increases the possibility of obtaining a natural breast form [2]. However, immediate reconstruction requires a longer period of general anesthesia and increases the risk of infection and hemorrhage, wound size, and healing time [22]. Delayed reconstruction, on the other hand, allows the patient additional time to consider her restorative options.

Reconstruction can be performed after completion of systemic cancer treatment. If so, it will be known if the patient received radiotherapy, and there will be shorter hospitalization and recovery times because the reconstruction does not occur at the same time as the mastectomy. Less dissection is performed, and the risk of skin necrosis is greatly reduced. In this situation, the woman can choose the timing of her surgery and plan for the inevitable interruptions in her daily life with consideration of personal, professional, and family responsibilities. Disadvantages of delayed reconstruction include additional surgery and the negative psychological effects from suffering from body disfigurement for a period of time [20, 23].

The advantages of expander-implant techniques for breast reconstruction also include minimal morbidity compared with the donor site damage with autologous flap reconstruction techniques and the saving of surrounding skin tissue flaps, which remain available for use in different reconstruction techniques $[13,24]$.

A technical modification to TE-based breast reconstruction is the use of the acellular dermal matrix (ADM) of either human or bovine origin, which allows creation of the submuscular pocket by mobilization of only the pectoralis major muscle $[25,26]$. The use of ADM provides numerous advantages over the conventional technique, but there are also potential disadvantages, including higher cost [27]. More recently, autologous dermal grafts have been proposed as an alternative to ADM [28, 29].

The ADM, which may be of fetal bovine, porcine, or human cadaver origin, acts as a "pectoralis extender," covering the inferolateral portion of the TE and obviating the need for elevation of the serratus anterior muscle, the pectoralis minor muscle, and the rectus abdominis fascia [25, 30-35]. The ADM is typically a $8 \times 16 \mathrm{~cm}$ sheet of dermal matrix that is sutured to the detached pectoralis major muscle edge and functions as a sling or hammock for the TE. Advocates of ADM point out the many advantages deriving from its use, for example, larger pocket size, higher intraoperative fill volume (even double) [36], increased expansion and enhanced definition of the lower pole, resulting in more natural shape and ptosis, less lower pole rippling, increased control over the IMF and the lateral mammary border, reduced postoperative pain, faster postoperative expansion, and lower capsular contracture formation [37-50]. However, these aesthetic advantages have mostly been accepted on the basis of empirical or anecdotal evidence [51-53]. Some authors have reported increased early complication rates (hematoma, seroma formation, and infection) with the use of 
ADM [42, 54]. Moreover, in a recent review, Kim et al. [55] reported acceptable complication rates of $8.6 \%-19.5 \%$ after $\mathrm{ADM}$ breast reconstruction.

Autologous fat grafting is an increasingly popular technique used in reconstructive surgery of the breast. Autologous fat grafting can be used for simple, aesthetic augmentation of the breast, correction of breast asymmetry, and correction of breast deformities, as an adjunct or primary tool in breast reconstruction, and for soft tissue coverage of breast implants [56]. An increasing number of authors proposed that lipofilling could improve the outcomes of total or partial reconstruction in breast cancer patients [56-58].

Although several teams have used repeated lipofilling sessions for total breast reconstruction, most authors consider that the lipofilling technique is indicated for the local improvement of small defects or asymmetry only [58-60].

Most recently, some authors have proposed the preoperative use of vacuum-based external tissue expander (i.e., Brava device) followed by autologous fat grafting, like an alternative to partial and total breast reconstruction [61-64]. After some weeks of Brava expansion, the breast volume increased by 100 to 300 percent and the authors diffusely grafted the breasts with 100 to $400 \mathrm{ml}$ of lipoaspirate. The addition of Brava expansion before autologous fat grafting leads significantly to larger breast augmentation, with more fat graft placement, higher graft survival rate, and minimal graft necrosis. The device was well tolerated by patients, with satisfying aesthetic results; however, they experienced a higher incidence of skin complication, in particular in irradiated patients [61-64].

\section{Materials and Methods}

2.1. Surgical Technique. The first step is preoperative planning, during which breast dimensions, NAC position, and the areola to inframammary fold distance are evaluated to establish the ideal breast size and ptosis degree. During the evaluation, the possible reconstruction options are discussed, not only for the affected breast, but also for the contralateral breast. Augmentation, reduction, and nonintervention are all therapeutic possibilities.

The complexity of the decision-making process that precedes breast reconstruction surgery has increased due to the great range of reconstruction strategies available today [65-67]. Less-experienced surgeons can use algorithms, flow charts, and nomograms to help them plan surgery [68-70]. More recently, surgical planning systems have been devised as well as virtual simulator systems to train surgeons outside of the "apprenticeship model" [71-73].

The size of the device is based on breast width and size and the contralateral breast shape, but one must also consider patient wishes for the contralateral technique [13]. The surgeon must be aware that the patient's main concern is her attractiveness after breast reconstruction and that the final breast size should correspond with body size and influences patient satisfaction with her self-image [74].

The technique requires two stages: a temporary device (tissue expander) is placed in a submuscular pocket during the first operation if immediate breast reconstruction is performed and at the first stage if delayed reconstruction is performed. After sufficient healing has occurred, the expander is filled with saline in a serial fashion over several weeks or months to the desired volume. Then, after there has been sufficient expansion, the patient returns to the operating room for removal of the expander and replacement with a permanent saline or silicone implant $[2,8]$.

2.1.1. First Stage. When the mastectomy is finished, it is possible to start with the reconstruction step. If the mastectomy flap is deemed viable, the surgeon can proceed with immediate reconstruction by creating a pocket for a tissue expander. Either a partial or a complete submuscular pocket is created, with the same dimensions as the selected expander. The chosen expander should have the same base width and height as the contralateral breast. It is important to avoid implant visibility or exposure; thus, complete soft tissue coverage of the expander must be ensured.

After mammary gland removal, a new evaluation of the quality of the remaining skin and muscle is performed. It is important to redefine the edge of the pocket and the inframammary fold position, comparing them with the size of the expander previously chosen.

The patient is positioned on the operating table with the upper arm adducted to $60^{\circ}$ to obtain complete relaxation of the pectoralis major and to facilitate muscle dissection. The contralateral breast should be visible in order to obtain the best possible symmetry during reconstruction. Pectoralis major dissection starts from its lateral edge, followed by the superior, medial, and inferior borders. Inferolaterally, the aponeurosis of the anterior rectus muscle and the external oblique is exposed. Finally, the muscle is dissected from its sternal attachment at the level of the second intercostal space. At this point, the pectoralis major can be elevated to create a superior pocket. Dissection of the pectoralis major muscle is easy and minimally traumatic to the patient.

The traditional approach to creating a pocket for the expander and implant is to optimize muscle coverage (Figure 1) [75]. Accordingly, both the pectoralis major and the entirety of the serratus are initially raised [76]. However, raising the serratus muscle completely off the ribs leaves a surface overlying the chest wall that is painful and not ideally suited for the sutures that would subsequently define the inferolateral aspect of the reconstructed breast. An alternative is the creation of a musculofascial pocket in which the whole pectoralis muscle composes the superior portion but laterally includes only a part of the serratus muscle with its entire overlying fascia. This dissection allows adequate space for the tissue expander without the risk of it folding on itself [77]. A drain should be placed into the pocket before the expander. It should be immersed in iodopovidone or antibiotic solution, correctly oriented, and placed into the mastectomy cavity. Finally, the pocket is closed with reabsorbable interrupted sutures [13].

The expander is completely evacuated of any retained air and then inflated with saline up to $20 \%-30 \%$ of its final volume to facilitate its insertion into the pocket. After the intervention, the expander is inflated to approximately $50 \%$ of the total volume to expedite the expansion process and 


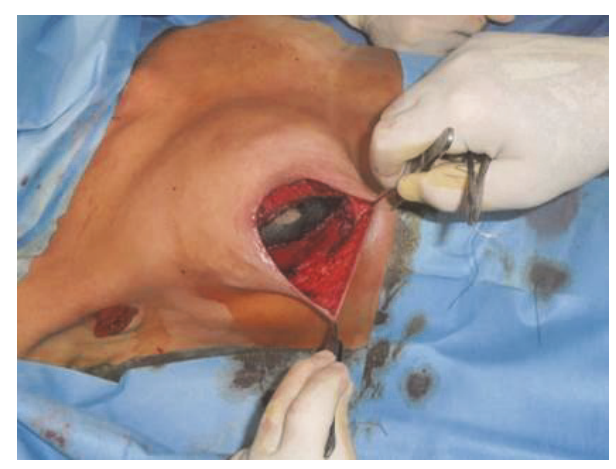

FIgURE 1: Implant placement into the submuscular pocket.

decrease the risk of postoperative hematoma and seroma. The increase in intraoperative fill does not increase the rate of mastectomy flap failure $[78,79]$.

Expansion time may vary between 3 and 7 months. Generally, the tissue expanders used for breast reconstruction are anatomically shaped, and the lower pole can be further expanded. Full-projection of the tissue expanders helps recruit upper pole tissue to highly expand the lower pole, giving a naturally ptotic appearance to the reconstructed breast [80]. Overexpansion by approximately $30 \%$ is needed to obtain an acceptable degree of breast ptosis $[8,15]$.

2.1.2. Second Stage. The second stage is commonly performed at least 6 months after the end of tissue expansion [81]. The mastectomy scar is normally removed and new access is created at the same site. Subcutaneous and muscular dissection is performed to enter the pocket and remove the tissue expander, previously emptied.

An important part of the exchange procedure is setting the inframammary fold and the inferolateral extent of the implant pocket. The inframammary fold is the most critical visual landmark of the breast, and the entire final reconstruction is based on this landmark. After the expander is removed, the inframammary is set using a suture that fixes the deep dermis to the anterior chest wall. Needles are inserted into the pouch through the skin to mark it. The shape is reconstructed with several sutures, creating an aesthetically pleasing curve inferolaterally.

In addition to defining the inframammary fold, the sutures create a fixed edge that prevents the implant from migrating laterally. Radial capsulotomy is more commonly performed to allow centripetal release of the breast. However, circumferential capsulotomy allows obtainment of an increase in projection from 1 to $7 \mathrm{~cm}[36,77]$.

The permanent implant can be filled with saline solution or silicone gel; the US Food and Drug Administration approved silicone in 2012. The surgeon can choose either silicone-filled shaped implants or round implants to promote a natural aesthetic outcome [82]. The most common implant type currently used is a prosthesis filled with a very dense silicone gel, called highly cohesive. The firmness of the filler material prevents capsular contracture and preserves the original shape of the implant.
When the selected prosthesis is inserted, the appearance and symmetry with the contralateral breast are checked with the patient in the sitting position [13]. Finally, the wound is closed with double-layered absorbable suture material.

\section{Results}

Mastectomy is a destructive but essential intervention for women with breast cancer.

Tissue expansion breast reconstruction is a safe, reliable, and efficacious procedure with considerable psychological benefits since it provides a healthy body image $[78,79,83]$.

More realistic reconstruction, even in patients with aggressive surgical resections, can now be obtained due to advances in cohesive-silicone implants. Even though autologous breast reconstruction provides a better cosmetic outcome with a more natural-appearing breast, tissue expanderbased reconstructions have the advantages of shorter operative times, faster recovery, and lack of donor site morbidity. Moreover, the aesthetic result obtained with tissue-expander reconstruction is considered more than acceptable by most patients (Figure 2) [84].

Acquired contour deformities after breast reconstruction are relatively common and occur independent of the technique used, presenting a frequent therapeutic challenge to reconstructive surgeons [85]. The transplantation of autologous adipose tissue is a simple and effective solution for many immediate or delayed postoperative complications, such as for defining the inframammary fold, correcting profile asymmetry, or filling neobreast defects. In addition to adipocytes, cell types such as fibroblasts, smooth muscle cells, endothelial cells, and preadipocytes compose the fat graft. Stem cells isolated from lipoaspirates have demonstrated in vitro adipogenic, chondrogenic, osteogenic, and myogenic lineage commitments $[86,87]$ and have shown differentiation into pancreatic cells, hepatocytes, and neurogenic cells [8890].

The stromal vascular fraction of the fat graft has an important regenerative function and is also responsible for the paracrine secretion of various factors such as VEGF, HGF, and TGF- $\beta$. These factors are released in response to different stimuli, including hypoxia. They strongly influence stem cell differentiation, induce angiogenesis and tissue remodelling, and stimulate wound healing $[91,92]$.

There is no standardized protocol for isolating AdiposeDerived Stem Cells (ASCs) for clinical application. In fact, in the literature, it is possible to find different methods described based on fat centrifugation with or without the addition of collagenase or other enzymatic reagents [93-105].

\section{Conclusion}

Tissue-expander reconstruction is a safe and effective technique chosen by many patients. It is an attractive option due to the lack of a donor defect, reduced recovery time and potential morbidity, and the fact that it allows women to exercise choice in the size of the reconstructed breast. 


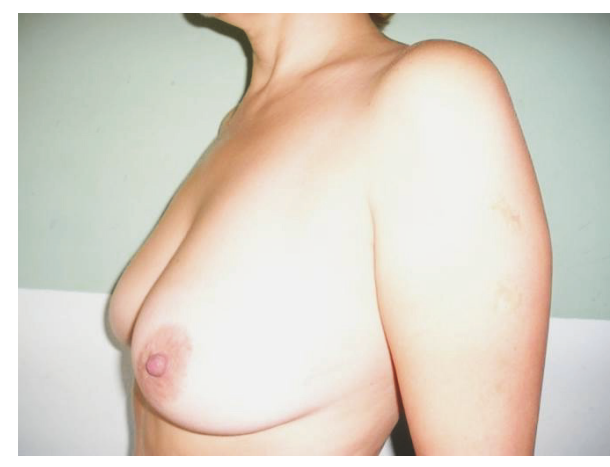

(a)

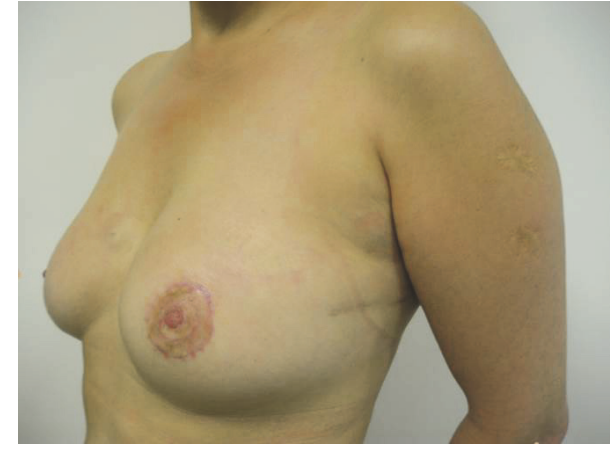

(b)

Figure 2: (a) A 45-year-old patient before mastectomy and reconstruction surgery. (b) The same patient after tissue expansion and implant reconstruction, showing the final result.

\section{Additional Points}

This paper is a description of the important psychological effect of breast cancer surgery, a focus on the most common surgical reconstruction technique and analysis of esthetic and psychologic results.

\section{Conflicts of Interest}

The authors declare that there are no conflicts of interest regarding the publication of this paper.

\section{References}

[1] K. McPherson, C. M. Steel, and J. M. Dixon, "Breast cancerepidemiology, risk factors, and genetics," British Medical Journal, vol. 321, no. 7261, pp. 624-628, 2000.

[2] S. Lamp and J. L. Lester, "Reconstruction of the breast following mastectomy," Seminars in Oncology Nursing, vol. 31, no. 2, pp. 134-145, 2015.

[3] V. Guyomard, S. Leinster, and M. Wilkinson, "Systematic review of studies of patients' satisfaction with breast reconstruction after mastectomy," The Breast, vol. 16, no. 6, pp. 547-567, 2007.

[4] S. Potter and Z. Winters, "Does breast reconstruction improve quality of life for women facing mastectomy? A systematic review," European Journal of Surgical Oncology, vol. 34, no. 10, p. 1181, 2008.

[5] Z. Roje, S. Jankovic, and M. Ninkovic, "Breast Reconstruction after Mastectomy," Collegium Antropologicum, vol. 1, pp. 113$123,2010$.

[6] C. M. McCarthy, B. J. Mehrara, E. Riedel et al., "Predicting complications following expander/implant breast reconstruction: an outcomes analysis based on preoperative clinical risk," Plastic and Reconstructive Surgery, vol. 121, no. 6, pp. 1886-1892, 2008.

[7] J. Nolan, R. A. Jenkins, K. Kurihara, and R. C. Schultz, “The acute effects of cigarette smoke exposure on experimental skin flaps," Plastic and Reconstructive Surgery, vol. 75, no. 4, pp. 544549, 1985.

[8] B. Kaya and S. Serel, "Breast Reconstruction," Experimental Oncology, vol. 35, pp. 280-286, 2013.
[9] T. D. Cronin and F. J. Gerow, "Augmentation mammaplasty: A new natural feel prostheses," in Excerpta Medica International Congress Series, vol. 66, pp. 41-46, 1963.

[10] T. D. Cronin, "Subcutaneous Mastectomy and Gel Implants," AORN Journal, vol. 10, no. 4, pp. 81-85, 1969.

[11] C. Radovan, "Breast reconstruction after mastectomy using the temporary expander," Plastic and Reconstructive Surgery, vol. 69, no. 2, pp. 195-206, 1982.

[12] C. Radovan, "Reconstruction of the breast after radical mastectomy using temporary expander," Plastic Surgery Forum, vol. 1, p. $41,1978$.

[13] M. B. Nava, G. Catanuto, A. Pennati, Cividin V. V., and A. Spano, "Expander-implants breast reconstruction," in Plastic Surgery, P. C. Neligan, Ed., pp. 336-369, Elsevier Ltd, New York, NY, USA, 3rd edition, 2013.

[14] C. R. Albornoz, P. B. Bach, B. J. Mehrara et al., "A paradigm shift in U.S. Breast reconstruction: increasing implant rates," Plastic and Reconstructive Surgery, vol. 131, no. 1, pp. 15-23, 2013.

[15] A. N. Mesbahi, C. M. McCarthy, and J. J. Disa, "Breast reconstruction with prosthetic implants," Cancer Journal, vol. 14, no. 4, pp. 230-235, 2008.

[16] G. P. Maxwell and P. A. Falcone, "Eighty-four consecutive breast reconstructions using a textured silicone tissue expander," Plastic and Reconstructive Surgery, vol. 89, no. 6, pp. 1022-1034, 1992.

[17] S. L. Spear and C. V. Pelletiere, "Immediate breast reconstruction in two stages using textured, integrated-valve tissue expanders and breast implants," Plastic and Reconstructive Surgery, vol. 113, no. 7, pp. 2098-2103, 2004.

[18] S. L. Spear and A. Majidian, "Immediate breast reconstruction in two stages using textured, integrated-valve tissue expanders and breast implants: A retrospective review of 171 consecutive breast reconstructions from 1989 to 1996," Plastic and Reconstructive Surgery, vol. 101, no. 1, pp. 53-63, 1998.

[19] S. L. Spear, J. M. Economides, J. Shuck, and K. M. Patel, “Analyzing implant movement with tabbed and nontabbed expanders through the process of two-stage breast reconstruction," Plastic and Reconstructive Surgery, vol. 133, no. 3, 2014.

[20] S. L. Spear and A. N. Mesbahi, "Implant-Based Reconstruction," Clinics in Plastic Surgery, vol. 34, no. 1, pp. 63-73, 2007.

[21] K. A. Metcalfe, T. Zhong, S. A. Narod et al., "A prospective study of mastectomy patients with and without delayed breast reconstruction: long-term psychosocial functioning in the breast 
cancer survivorship period," Breast Disease, vol. 111, no. 2, pp. 258-264, 215.

[22] A. Alderman, K. Gutowski, A. Ahuja, and D. Gray, "ASPS clinical practice guideline summary on breast reconstruction with expanders and implants," Plastic and Reconstructive Surgery, vol. 134, no. 4, pp. 648e-655e, 2014.

[23] S. S. Kroll and B. Baldwin, "A comparison of outcomes using three different methods of breast reconstruction," Plastic and Reconstructive Surgery, vol. 90, no. 3, pp. 455-462, 1992.

[24] E. Demiri, D. Dionyssiou, S. Sapountzis, L. Pavlidis, I. Natsiopoulos, and S. Miliaras, "Becker Expander-Based Breast Reconstruction Following Wise Pattern Skin-Reducing Mastectomy: Complication Rates and Risk Factors," Aesthetic Plastic Surgery, vol. 41, no. 2, pp. 304-311, 2017.

[25] K. H. Breuing and S. M. Warren, "Immediate bilateral breast reconstruction with implants and inferolateral AlloDerm slings," Annals of Plastic Surgery, vol. 55, no. 3, pp. 232-239, 2005.

[26] C. B. Basu, M. Leong, and M. J. Hicks, "Acellular cadaveric dermis decreases the inflammatory response in capsule formation in reconstructive breast surgery," Plastic and Reconstructive Surgery, vol. 126, no. 6, pp. 1842-1847, 2010.

[27] T. L. Hartzell, A. H. Taghinia, J. Chang, S. J. Lin, and S. A. Slavin, "The use of human acellular dermal matrix for the correction of secondary deformities after breast augmentation: Results and costs," Plastic and Reconstructive Surgery, vol. 126, no. 5, pp. 1711-1720, 2010.

[28] D. A. Hudson, K. G. Adams, and S. Adams, "Autologous dermal graft in breast reconstruction," Annals of Plastic Surgery, vol. 68, no. 3, pp. 253-256, 2012.

[29] P. Maguina, R. Hoffman, and S. Szczerba, "Autologous dermal graft in breast reconstruction and treatment of breast implant malposition," Plastic and Reconstructive Surgery, vol. 125, no. 4, 2010.

[30] C. A. Salzberg, "Nonexpansive immediate breast reconstruction using human acellular tissue matrix graft (AlloDerm)," Annals of Plastic Surgery, vol. 57, no. 1, pp. 1-5, 2006.

[31] A. S. Colwell, B. Damjanovic, B. Zahedi, L. Medford-Davis, C. Hertl, and W. G. Austen, "Retrospective review of 331 consecutive immediate single-stage implant reconstructions with acellular dermal matrix: Indications, complications, trends, and costs," Plastic and Reconstructive Surgery, vol. 128, no. 6, pp. 1170-1178, 2011.

[32] A. K. Antony, C. M. McCarthy, P. G. Cordeiro et al., "Acellular human dermis implantation in 153 immediate two-stage tissue expander breast reconstructions: Determining the incidence and significant predictors of complications," Plastic and Reconstructive Surgery, vol. 125, no. 6, pp. 1606-1614, 2010.

[33] R. Endress, M. S. S. Choi, and G. K. Lee, "Use of fetal bovine acellular dermal xenograft with tissue expansion for staged breast reconstruction," Annals of Plastic Surgery, vol. 68, no. 4, pp. 338-341, 2012.

[34] M.-H. Zheng, J. Chen, Y. Kirilak, C. Willers, J. Xu, and D. Wood, "Porcine small intestine submucosa (SIS) is not an acellular collagenous matrix and contains porcine DNA: possible implications in human implantation," Journal of Biomedical Materials Research Part B: Applied Biomaterials, vol. 73, no. 1, pp. 61-67, 2005.

[35] S. L. Spear, P. M. Parikh, E. Reisin, and N. G. Menon, "Acellular dermis-assisted breast reconstruction," Aesthetic Plastic Surgery, vol. 32, no. 3, pp. 418-425, 2008.
[36] J. D. McCue, M. Migliori, and B. L. Cunningham, "Expanders and breast reconstruction with gel and saline implants," Aesthetic and Reconstructive Surgery of the Breast, pp. 29-50, 2010.

[37] J. W. Parks, S. E. Hammond, W. A. Walsh, R. L. Adams, R. G. Chandler, and E. A. Luce, "Human acellular dermis versus no acellular dermis in tissue expansion breast reconstruction," Plastic and Reconstructive Surgery, vol. 130, no. 4, pp. 739-746, 2012.

[38] R. J. Zienowicz and E. Karacaoglu, "Implant-based breast reconstruction with allograft," Plastic and Reconstructive Surgery, vol. 120, no. 2, pp. 373-381, 2007.

[39] B. M. Topol, E. F. Dalton, T. Ponn, and C. J. Campbell, "Immediate single-stage breast reconstruction using implants and human acellular dermal tissue matrix with adjustment of the lower pole of the breast to reduce unwanted lift," Annals of Plastic Surgery, vol. 61, no. 5, pp. 494-499, 2008.

[40] V. Bindingnavele, M. Gaon, K. S. Ota, D. A. Kulber, and D.-J. Lee, "Use of acellular cadaveric dermis and tissue expansion in postmastectomy breast reconstruction," Journal of Plastic, Reconstructive \& Aesthetic Surgery, vol. 60, no. 11, pp. 1214-1218, 2007.

[41] H. Sbitany, S. N. Sandeen, A. N. Amalfi, M. S. Davenport, and H. N. Langstein, "Acellular dermis-assisted prosthetic breast reconstruction versus complete submuscular coverage: A headto-head comparison of outcomes," Plastic and Reconstructive Surgery, vol. 124, no. 6, pp. 1735-1740, 2009.

[42] Y. S. Chun, K. Verma, H. Rosen et al., "Implant-based breast reconstruction using acellular dermal matrix and the risk of postoperative complications," Plastic Reconstructive Surgery, vol. 125, pp. 429-436, 2010.

[43] S. Becker, M. Saint-Cyr, C. Wong et al., "AlloDerm versus dermamatrix in immediate expander-based breast reconstruction: A preliminary comparison of complication profiles and material compliance," Plastic and Reconstructive Surgery, vol. 123, no. 1, pp. 1-6, 2009.

[44] C. F. Bellows, D. Albo, D. H. Berger, and S. S. Awad, "Abdominal wall repair using human acellular dermis," The American Journal of Surgery, vol. 194, no. 2, pp. 192-198, 2007.

[45] B. Buinewicz and B. Rosen, "Acellular Cadaveric Dermis (AlloDerm): A New Alternative for Abdominal Hernia Repair," Annals of Plastic Surgery, vol. 52, no. 2, pp. 188-194, 2004.

[46] J. Y. S. Kim, D. W. Buck, O. Kloeters, S. Eo, and N. F. Jones, "Reconstruction of a recurrent first dorsal web space defect using acellular dermis," HAND, vol. 2, no. 4, pp. 240-244, 2007.

[47] J. Y. Kim, J. M. Bullocks, C. B. Basu et al., "Dermal composite flaps reconstructed from acellular dermis: a novel method of neourethral reconstruction," Plastic and Reconstructive Surgery, vol. 115, no. 7, pp. 96e-100e, 2005.

[48] C. E. Butler, H. N. Langstein, and S. J. Kronowitz, "Pelvic, abdominal, and chest wall reconstruction with AlloDerm in patients at increased risk for mesh-related complications," Plastic and Reconstructive Surgery, vol. 116, no. 5, pp. 1263-1275, 2005.

[49] K. Heyer, D. W. Buck, C. Kato, S. A. Khan, M. Alam, and J. Y. S. Kim, "Reversed acellular dermis: Failure of graft incorporation in primary tissue expander breast reconstruction resulting in recurrent breast cellulitis," Plastic and Reconstructive Surgery, vol. 125, no. 2, 2010.

[50] A. Losken, "Early results using sterilized acellular human dermis (neoform) in postmastectomy tissue expander breast reconstruction," Plastic and Reconstructive Surgery, vol. 123, no. 6, pp. 1654-1658, 2009. 
[51] S. L. Spear, M. E. Carter, and J. C. Ganz, "The correction of capsular contracture by conversion to "dual-plane" positioning: Technique and outcomes," Plastic and Reconstructive Surgery, vol. 112, no. 2, pp. 456-466, 2003.

[52] T. J. Nguyen, J. N. Carey, and A. K. Wong, "Use of human acellular dermal matrix in implant- based breast reconstruction: evaluating the evidence," Journal of Plastic, Reconstructive \& Aesthetic Surgery, vol. 64, no. 12, pp. 1553-1561, 2011.

[53] J. D. Namnoum, "Expander/implant reconstruction with AlloDerm: recent experience," Plastic and Reconstructive Surgery, vol. 124, no. 2, pp. 387-394, 2009.

[54] K. E. Weichman, S. C. Wilson, A. L. Weinstein et al., "The use of acellular dermal matrix in immediate two-stage tissue expander breast reconstruction," Plastic and Reconstructive Surgery, vol. 129, no. 5, pp. 1049-1058, 2012.

[55] J. Y. S. Kim, A. A. Davila, S. Persing et al., "A meta-analysis of human acellular dermis and submuscular tissue expander breast reconstruction," Plastic and Reconstructive Surgery, vol. 129, no. 1, pp. 28-41, 2012.

[56] S. R. Coleman and A. P. Saboeiro, "Fat grafting to the breast revisited: safety and efficacy," Plastic and Reconstructive Surgery, vol. 119, no. 3, pp. 775-785, 2007.

[57] M. A. Shiffman, Breast Reconstruction, Springer International Publishing, Cham, 2016.

[58] J.-Y. Petit, V. Lohsiriwat, and M. Rietjens, "Reply to about locoregional recurrence risk after lipofilling in breast cancer patients," Annals of Oncology, vol. 23, no. 3, pp. 803-804, 2012.

[59] O. Amar, C. Bruant-Rodier, S. Lehmann, V. Bollecker, and A. Wilk, "Fat tissue transplant: restoration of the mammary volume after conservative treatment of breast cancers, clinical and radiological considerations," Annales de Chirurgie Plastique Esthétique, vol. 53, no. 2, pp. 169-177, 2008.

[60] Y. Kijima, H. Yoshinaka, T. Owaki, and T. Aikou, "Early experience of immediate reconstruction using autologous free dermal fat graft after breast conservational surgery," Journal of Plastic, Reconstructive \& Aesthetic Surgery, vol. 60, no. 5, pp. 495-502, 2007.

[61] R. K. Khouri, G. Rigotti, R. K. Khouri et al., “Tissue-engineered breast reconstruction with Brava-assisted fat grafting: a 7-year, 488-patient, multicenter experience," Plastic and Reconstructive Surgery, vol. 135, no. 3, pp. 643-658, 2015.

[62] R. Khouri and D. Del Vecchio, "Breast reconstruction and augmentation using pre-expansion and autologous fat transplantation," Clinics in Plastic Surgery, vol. 36, no. 2, pp. 269-280, 2009.

[63] H. Uda, Y. Sugawara, S. Sarukawa, and A. Sunaga, "Brava and autologous fat grafting for breast reconstruction after cancer surgery," Plastic and Reconstructive Surgery, vol. 133, no. 2, pp. 203-213, 2014.

[64] R. K. Khouri, M. Eisenmann-Klein, and E. Cardoso, "Brava and autologous fat transfer is a safe and effective breast augmentation alternative: results of a 6-year, 81-patient, prospective multicenter study," Plastic and Reconstructive Surgery, vol. 129, no. 5, pp. 1173-1187, 2012.

[65] H. Bulam, S. Tuncer, and S. Ayhan, "Cosmetic outcome and percentage of breast volume excision in oncoplastic breastconserving surgery: a proposal," World Journal of Surgery, vol. 34, no. 9, pp. 1447-1452, 2010.

[66] K. B. Clough, T. Ihrai, S. Oden, G. Kaufman, E. Massey, and C. Nos, "Oncoplastic surgery for breast cancer based on tumour location and a quadrant-per-quadrant atlas," British Journal of Surgery, vol. 99, no. 10, pp. 1389-1395, 2012.
[67] D. Mauri, N. Pavlidis, and J. P. A. Ioannidis, "Neoadjuvant versus adjuvant systemic treatment in breast cancer: a metaanalysis," Journal of the National Cancer Institute, vol. 97, no. 3, pp. 188-194, 2005.

[68] P. G. Cordeiro, C. R. Albornoz, B. McCormick et al., "What Is the Optimum Timing of Postmastectomy Radiotherapy in Two-Stage Prosthetic Reconstruction: Radiation to the Tissue Expander or Permanent Implant?" Plastic and Reconstructive Surgery, vol. 135, no. 6, pp. 1518-1526, 2015.

[69] K. B. Clough, G. J. Kaufman, C. Nos, I. Buccimazza, and I. M. Sarfati, "Improving breast cancer surgery: a classification and quadrant per quadrant atlas for oncoplastic surgery," Annals of Surgical Oncology, vol. 17, no. 5, pp. 1375-1391, 2010.

[70] S. J. Kronowitz, "Delayed-immediate breast reconstruction: Technical and timing considerations," Plastic and Reconstructive Surgery, vol. 125, no. 2, pp. 463-474, 2010.

[71] E. Raposio, F. Norat, A. Orefice et al., "Computer-based preoperative planning for breast reconstruction in the woman with unilateral breast hypoplasia," Minerva Chirurgica, vol. 57, pp. 711-714, 2002.

[72] E. Raposio, S. Cicchetti, M. Adami, R. G. Ciliberti, and P. L. Santi, "Computer planning for breast reconstruction by tissue expansion: An update," Plastic and Reconstructive Surgery, vol. 113, no. 7, pp. 2095-2097, 2004.

[73] I. Porro, A. Schenone, M. Fato, E. Raposio, E. Molinari, and F. Beltrame, "An integrated environment for plastic surgery support: Building virtual patients, simulating interventions, and supporting intraoperative decisions," Computerized Medical Imaging and Graphics, vol. 29, no. 5, pp. 385-394, 2005.

[74] E. Raposio, V. Belgrano, P. L. Santi, and C. Chiorri, "Which is the ideal breast size? some social clues for plastic surgeons," Annals of Plastic Surgery, vol. 76, no. 3, pp. 340-345, 2016.

[75] R. P. Gruber, R. A. Kahn, H. Lash, M. R. Maser, D. B. Apfelberg, and D. R. Laub, "Breast reconstruction following mastectomy: A comparison of submuscular and subcutaneous techniques," Plastic and Reconstructive Surgery, vol. 67, no. 3, pp. 312-317, 1981.

[76] J. J. Disa, D. D. Ad-El, S. M. Cohen, P. G. Cordeiro, and D. A. Hidalgo, "The premature removal of tissue expanders in breast reconstruction," Plastic and Reconstructive Surgery, vol. 104, no. 6, pp. 1662-1665, 1999.

[77] P. G. Cordeiro and L. Jazayeri, “Two-stage implant-based breast reconstruction: An evolution of the conceptual and technical approach over a two-decade period," Plastic and Reconstructive Surgery, vol. 138, no. 1, pp. 1-11, 2016.

[78] P. G. Cordeiro and C. M. McCarthy, "A single surgeon's 12-year experience with tissue expander/implant breast reconstruction: Part I. A prospective analysis of early complications," Plastic and Reconstructive Surgery, vol. 118, no. 4, pp. 825-831, 2006.

[79] P. G. Cordeiro and C. M. McCarthy, "A single surgeon's 12-year experience with tissue expander/implant breast reconstruction: Part II. An analysis of long-term complications, aesthetic outcomes, and patient satisfaction," Plastic and Reconstructive Surgery, vol. 118, no. 4, pp. 832-839, 2006.

[80] J. Fan, E. Raposio, J. Wang, and R. E. A. Nordström, “Development of the inframammary fold and ptosis in breast reconstruction with textured tissue expanders," Aesthetic Plastic Surgery, vol. 26, no. 3, pp. 219-222, 2002.

[81] P. G. Cordeiro, C. R. Albornoz, B. McCormick et al., "What Is the Optimum Timing of Postmastectomy Radiotherapy in Two-Stage Prosthetic Reconstruction: Radiation to the Tissue 
Expander or Permanent Implant?" Plastic and Reconstructive Surgery, vol. 135, no. 6, pp. 1509-1517, 2015.

[82] N. Bertozzi, F. Simonacci, M. P. Grieco, E. Grignaffini, and E. Raposio, "The biologicaland clinical basis for the use of adiposederived stem cells in the field ofwound healing," Annals of Medicine and Surgery, vol. 20, pp. 41-48, 2017.

[83] E. Bellini, M. P. Grieco, and E. Raposio, "The science behind autologous fat grafting," Annals of Medicine and Surgery, vol. 24, pp. 65-73, 2017.

[84] E. Raposio and R. Ciliberti, "Clinical use of adipose-derived stem cells: Europeanlegislative issues," Annals of Medicine and Surgery, vol. 24, pp. 61-64, 2017.

[85] F. Simonacci, N. Bertozzi, M. P. Grieco, E. Grignaffini, and E. Raposio, "Autologous fat transplantation for breast reconstruction: A literature review," Annals of Medicine and Surgery, vol. 12, pp. 94-100, 2016.

[86] E. Raposio, C. Guida, I. Baldelli et al., "Characterization and induction of human pre-adipocytes," Toxicology in Vitro, vol. 21, no. 2, pp. 330-334, 2007.

[87] E. Raposio, C. Guida, R. Coradeghini et al., "In vitro polydeoxyribonucleotide effects on human pre-adipocytes," Cell Proliferation, vol. 41, no. 5, pp. 739-754, 2008.

[88] C. Scanarotti, A. M. Bassi, M. Catalano et al., "Neurogeniccommitted human pre-adipocytes express CYP1A isoforms," Chemico-Biological Interactions, vol. 184, no. 3, pp. 474-483, 2010.

[89] M. G. Aluigi, R. Coradeghini, C. Guida et al., "Pre-adipocytes commitment to neurogenesis 1: Preliminary localisation of cholinergic molecules," Cell Biology International, vol. 33, no. 5, pp. 594-601, 2009.

[90] R. Coradeghini, C. Guida, C. Scanarotti et al., "A comparative study of proliferation and hepatic differentiation of human adipose-derived stem cells," Cells Tissues Organs, vol. 191, no. 6, pp. 466-477, 2010.

[91] G. Caruana, N. Bertozzi, E. Boschi, M. P. Grieco, E. Grignaffini, and E. Raposio, "Role of adipose-derived stem cells in chronic cutaneous wound healing," Annali Italiani Di Chirurgia, vol. 86, no. 1, pp. 1-4, 2015.

[92] E. Raposio, N. Bertozzi, S. Bonomini et al., "Adipose-derived stem cells added to platelet-rich plasma for chronic skin ulcer therapy," Wounds, vol. 28, no. 4, pp. 126-131, 2016.

[93] E. Raposio, G. Caruana, M. Petrella, S. Bonomini, and M. P. Grieco, "A standardized method of isolating adipose-derived stem cells for clinical applications," Annals of Plastic Surgery, vol. 76, no. 1, pp. 124-126, 2016.

[94] E. Raposio, G. Caruana, S. Bonomini, and G. Libondi, "A novel and effective strategy for the isolation of adipose-derived stem cells: minimally manipulated adipose-derived stem cells for more rapid and safe stem cell therapy," Plastic and Reconstructive Surgery, vol. 133, no. 6, pp. 1406-1409, 2014.

[95] E. Bellini, M. P. Grieco, and E. Raposio, "A journey through liposuction and liposculture: Review," Annals of Medicine and Surgery, vol. 24, pp. 53-60, 2017.

[96] F. Simonacci, N. Bertozzi, and E. Raposio, "Off-label use of adipose-derived stem cells," Annals of Medicine and Surgery, vol. 24, pp. 44-51, 2017.

[97] N. Bertozzi, M. Pesce, P. Santi, and E. Raposio, "One-Stage Immediate Breast Reconstruction: A Concise Review," BioMed Research International, vol. 2017, pp. 1-12, 2017.

[98] E. Raposio and N. Bertozzi, "How to isolate a ready-to-use adipose-derived stem cells pellet for clinical application," Eur Rev Med Pharmacol Sci, vol. 21, pp. 4252-4260, 2017.
[99] S. Polotto, M. P. Grieco, F. Simonacci et al., "Reduction mammoplasty techniques in post-bariatric patients: our experience," Acta Biomedica, vol. 88, pp. 156-160, 2017.

[100] M. Gardani, N. Bertozzi, M. P. Grieco et al., "Breast reconstruction with anatomical implants: A review of indications and techniques based on current literature," Annals of Medicine and Surgery, vol. 21, pp. 96-104, 2017.

[101] N. Bertozzi, M. Pesce, P. Santi, and E. Raposio, “Tissue expansion for breast reconstruction: Methods and techniques," Annals of Medicine and Surgery, vol. 21, pp. 34-44, 2017.

[102] E. Raposio, F. Simonacci, and R. E. Perrotta, "Adipose-derived stem cells: comparison between two methods of isolation for clinical applications," Annals of Medicine and Surgery, vol. 20, pp. 87-91, 2017.

[103] F. Simonacci, N. Bertozzi, M. P. Grieco, E. Grignaffini, and E. Raposio, "Procedure, applications, and outcomes of autologous fat grafting," Annals of Medicine and Surgery, vol. 20, pp. 49-60, 2017.

[104] N. Bertozzi, M. Pesce, P. Santi, and E. Raposio, "Oncoplastic breast surgery: comprehensive review," European Review for Medical and Pharmacological Sciences, vol. 21, pp. 2572-2585, 2017.

[105] E. Raposio and N. Bertozzi, "Isolation of Ready-to-Use Adipose-Derived Stem Cell (ASC) Pellet for Clinical Applications and a Comparative Overview of Alternate Methods for ASC Isolation," Current Protocols in Stem Cell Biology, vol. 16, no. 41, 2017. 


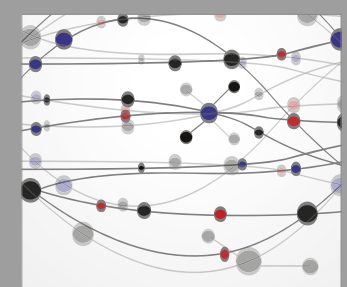

The Scientific World Journal
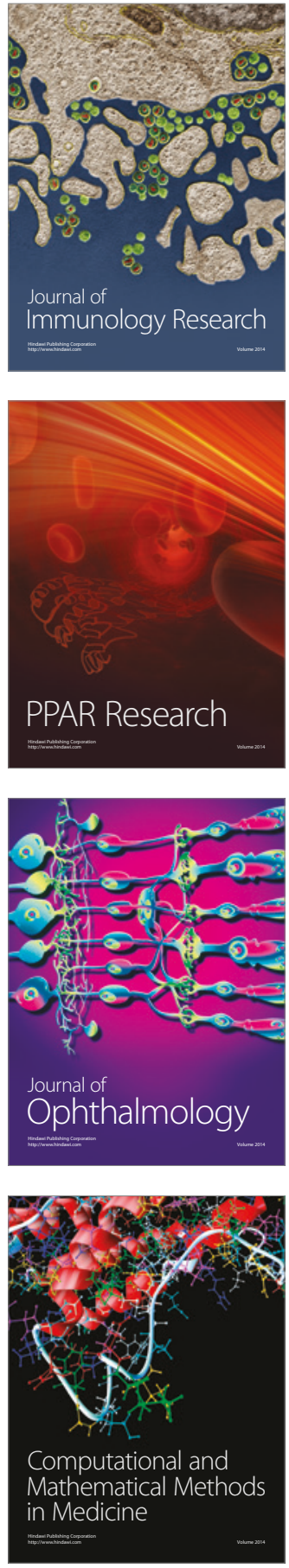

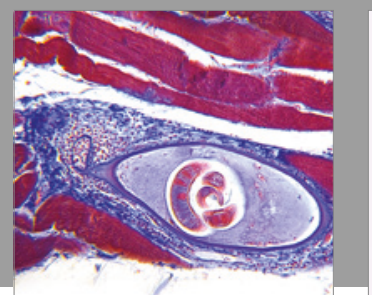

Gastroenterology Research and Practice
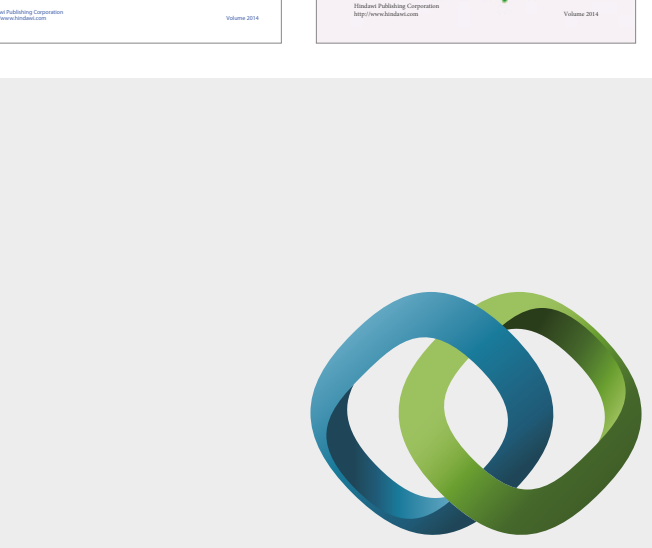

\section{Hindawi}

Submit your manuscripts at

https://www.hindawi.com
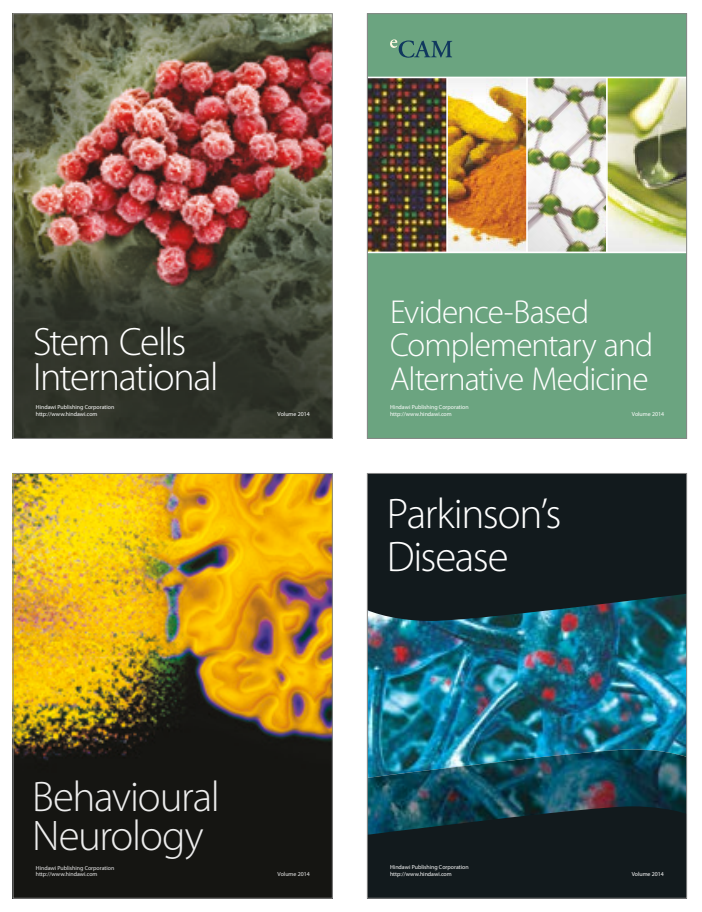
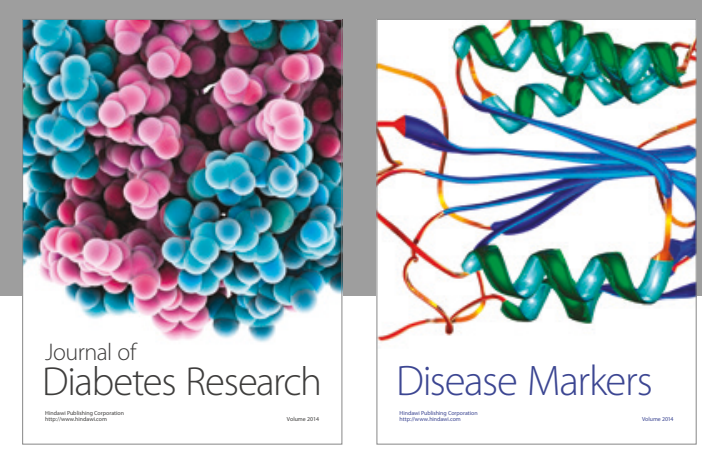

Disease Markers
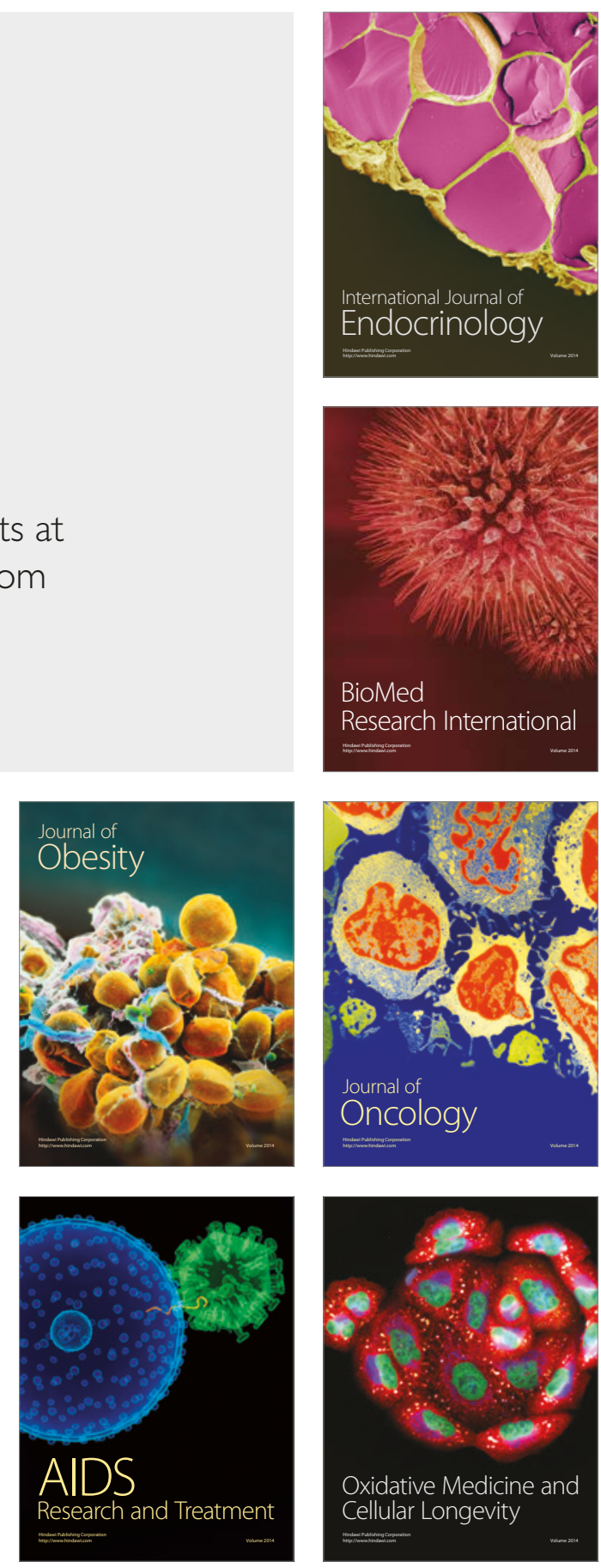